\title{
CASE STUDY OF NOISE AND
}

ITS REDUCTION

AWNY Y. ATTIA

The paper presents a case study of noise generation and its reduction as applied to a three phase induction motor. Noise: patterns of electric motors are of complex nature due to the different sources that are involved. Each of these sources can be detected from the noise spectra. These sources are mainly. mechanical, electromagnetic and aero-dynamic sources. As the author was involved in research investigation dealing with the mechanical noise sources, some experimental results are also presented giving the effects of changing the bearing preloading, clearances and the bracket stiffness on the noise level of the test motor. 

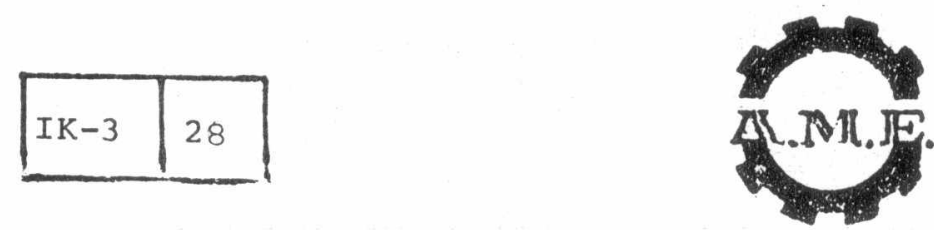

SECOND A.M.E. CONFERENCE

6 - 8 May 1986 , Cairo

\section{INTRODUCTION}

Noise is an objectionable form of sound. Higher speeds result in greater performance, reduced size, weight and cost but each of the three changes increases noise. In order to reduce noise, the sources of noise, its paths and receivers should be studied at first and means of noise reduction are recommended. Noise sources are mainly:

1. Mechanical sources as noise of bearings, gears, unbalanced components, etc.

2. Electromagnetic sources as noise of generators, transformers,

: circuit breakers, transmission lines, etc,

3. Aero-dynamic sources as noise of pumps, fet engines, aero- : planes, etc.

Noise reduction technlques are classified into:

1. Noise reduction at the source by reducing the amplitude of the forces generating noise, balancing rotating masses or use of damping materials.

2. Noise reduction at the transmission path, by increasing the distance between the sources and the receiver, by the use of barriers and enclosures or by absorption by acoustical materlal. 3. Use of ear protectors at the receiver, enclosures, etc.

\section{TEST CASE AND ANALYŚs}

The test case is the high noise pressure level that had been noticed after production and testing of an induction motor. The fjrst check is to detect the kind and sources of noise by: an ordinary stethoscope, put at different points on the motor casing. This preliminary checking revealed the existance of sirene noise indicating the aerodynamic source from the fan, huming indicating elctromagnetic noise from tis electric components and impact noise from the mechanical parts. The checking also showed that the overall noise pattern has a directivity emmitting from the pulley side of the motor.

1. I Noise of aero-aynamic origin:

is generally caused by the rotating impeller of the ventilating fan whentransferping the mechanical energy from the fan shaft to an air stream. The energy in the air appears in the form of. air velocity and air pressure. Noise level in this case dependis on the number of blades, fan speed and shape of air impulse. The noise spectrum appeared as tjpically broad band in character except for the fan blade frequency and harmonics.

1.2 Noise of magnetic sources:

is generally produced by magnetic effects resulting from periodic magnetic fleld which is almost exclusively in the air gap between the stator and rotor. These are due to many mechanical and electromagnetic properties of the stator-rotor assembly. They are resulting from:

a. The wave of the flux field for which the motor is designed. 


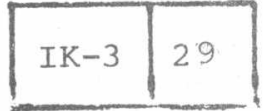

$r$
SECOND A M.E. CONFERENCE

6 - 8 May 1986 , Cairo

b. The number of slots in the rotor and in the stator and the difference between the two numbers.

c. Permeance variations of the alr gap caused by rotor slots and stator slots, the slot patterns and air gap eccentricities. d. The manner in which the coils of the pole windings are formed. e. The radial air gap length.

1.3 Noise of mechanical sources:

is generally caused by the bearings which are in most cases the main sources of noise. The bearing noise depends on the

- bearing type, speed, preload, overload and lubrication. Other

- sources of mechanical noise are the casing shape,material and.

- thickness and the vibrations of all rotating parts.

\section{EXPERIMENTAI WORK}

In order to divide the motor noise into some component noises, a motor was set with the possibility of removing the fan, replacing the ball bearingswith bearings of different sizes and types. Provisions were also made to change the motor casing with others of different shapes, thicknesses and materials. The tested motor was a 3 phase,A.C. 4 pole,2500 r.p.m. induction motor of the general layout shown in Fig. 1 .

Noise is picked by a condenser microphone in an anechoic room and noise level is amplified, analysed and recorded by a frequency wave analyser, audio frequency spectrometer and level - recorder. The layout of the measuring instruments is shown in. Fig. 2.

Noise Measurements were taken at 4 different points at $200 \mathrm{~mm}$ equidistant from the motor. Two measuring points werealong the motor shaft and the other two points in the normal direction along the line of symmetry of the motor.

The motor noises radiating at these four positions were recorded and analysed for the following different conditions:

a. Motor running with the fan and with the fan removed.

b. Motor running with different amounts of bearing preloading.

c. Motor running with different amounts of radial clearance.

: The same tests were repeated using sliding bearings instead of: rolling bearings.

\section{EXPERIMENTAL RESULTS}

\section{I CLASSIFICATION OF MOTOR NOISE}

Fig. (3.a) and (3.b) show samples of noise spectra of the test motor with the fan and without the fan respectively. From studying these spectra the sources of the different component noises could be detected and their properties classified as given in Table. 

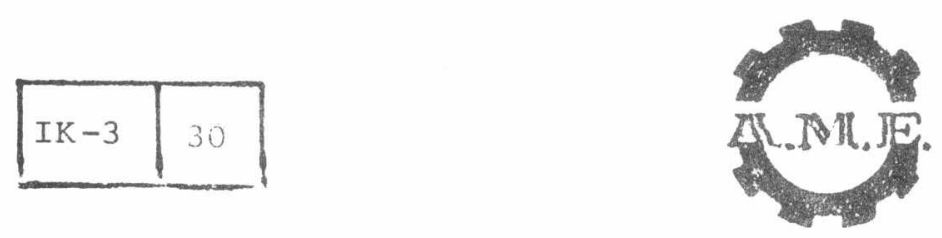

SECOND $T$ M.E. CONFERENCE

6 - 8 May 1986 , Cairo

$\Gamma$

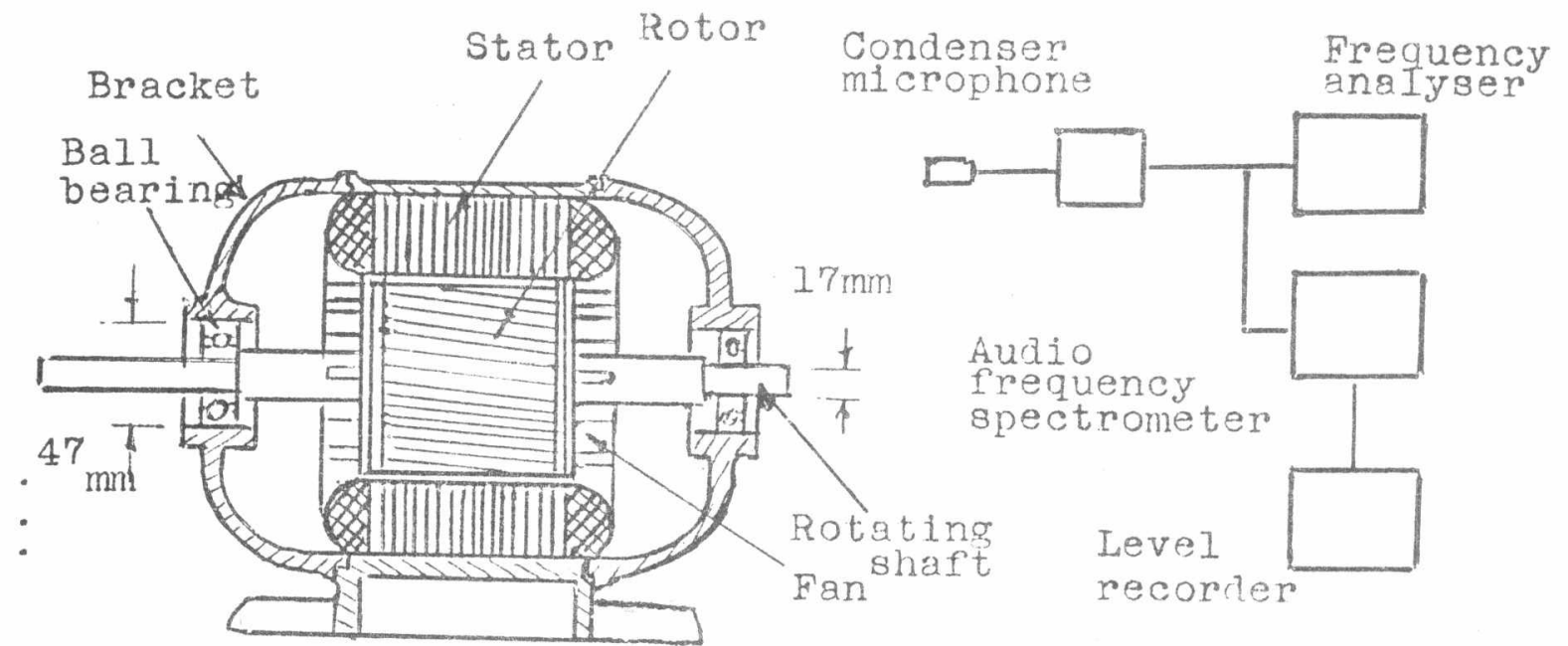

Fig. I Test Motor

Fig. 2 Noise measuring Apparatus

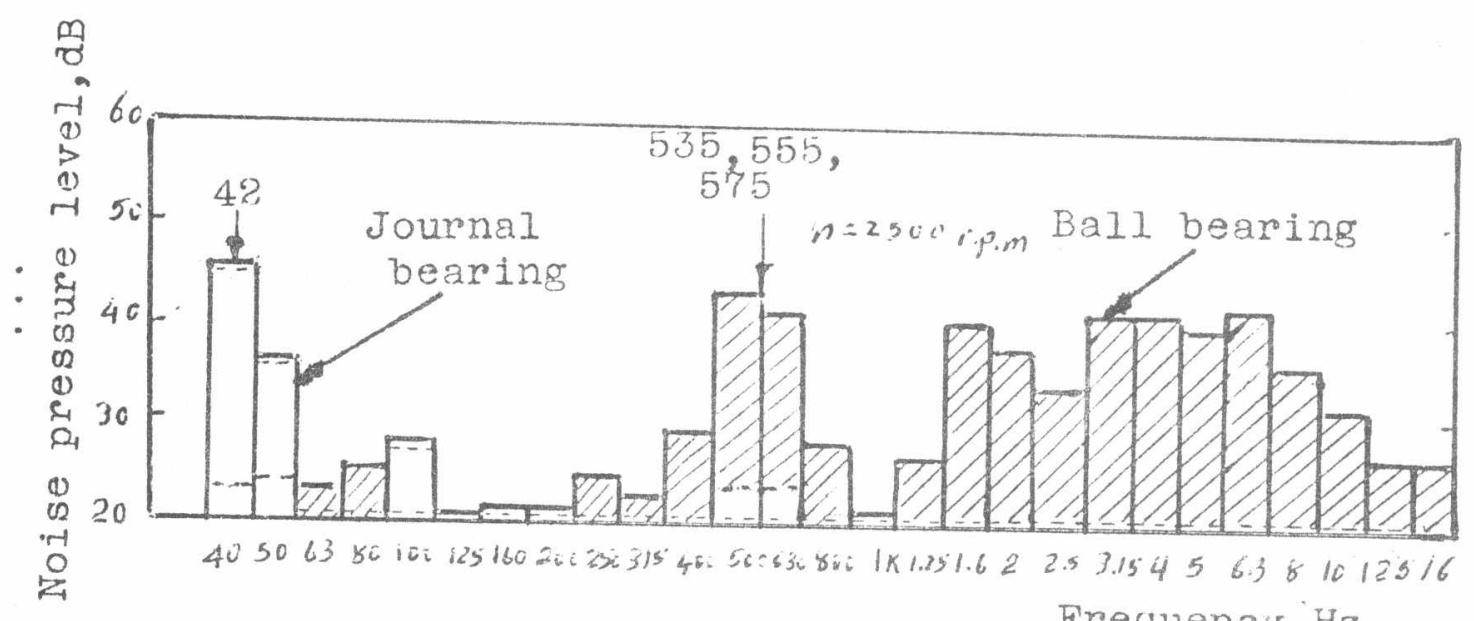

Fio. Frequency, $\mathrm{Hz}$ Fig. 3-a Motor noise spectrum showing effect

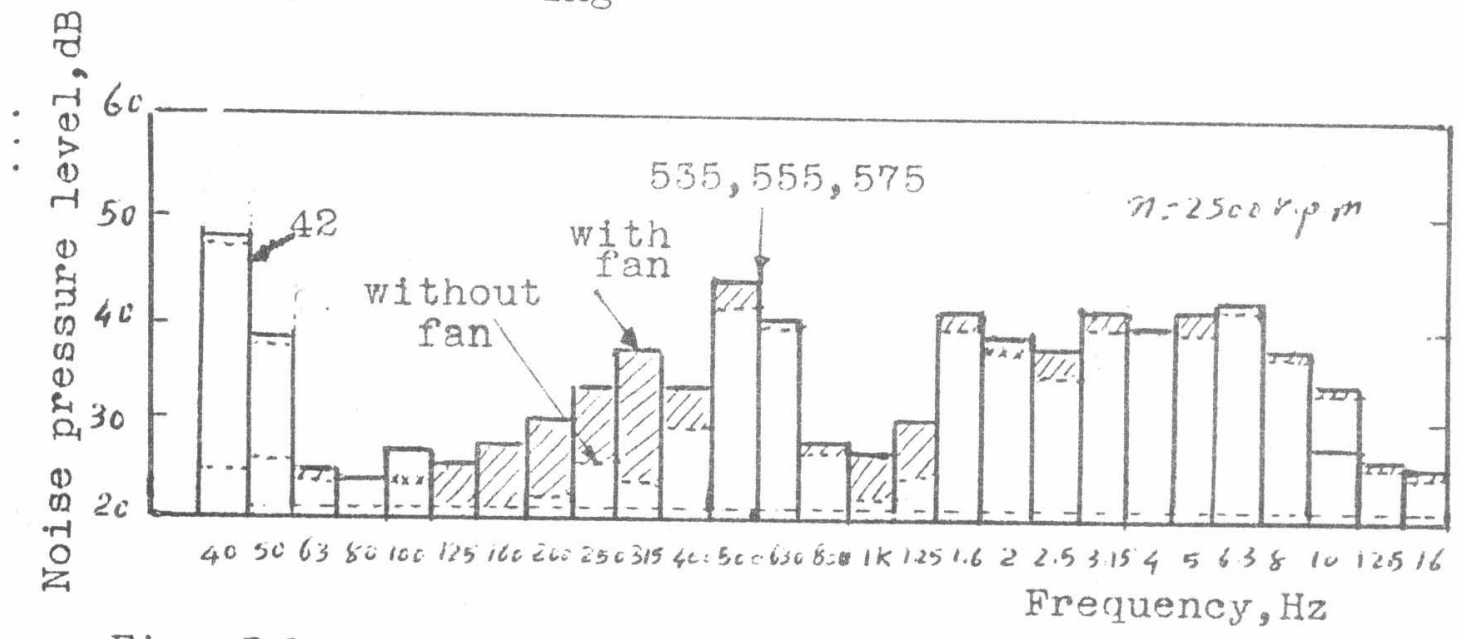

Fig. 3-b Motor noise spectrum showino affort 
SECOND A.M.E. CONFERENCE

6 - 8 May 1986 , Cairo

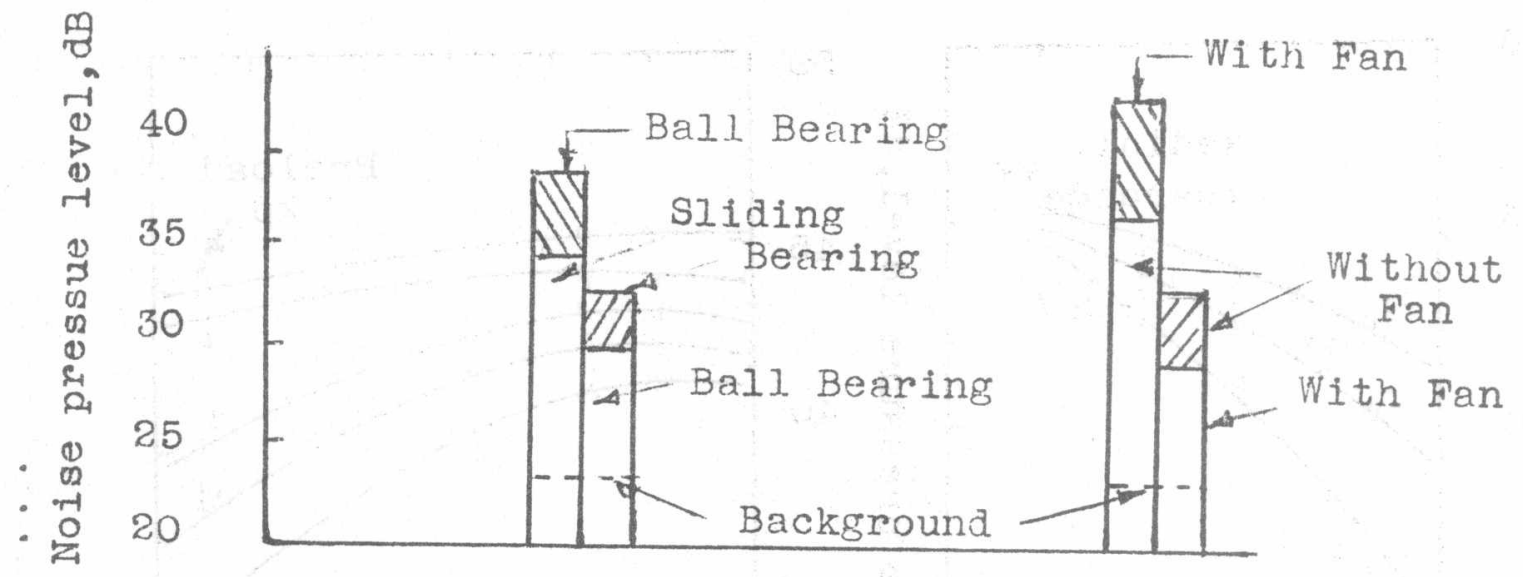

Fig. 4 Noise levels of test motor for different conditions

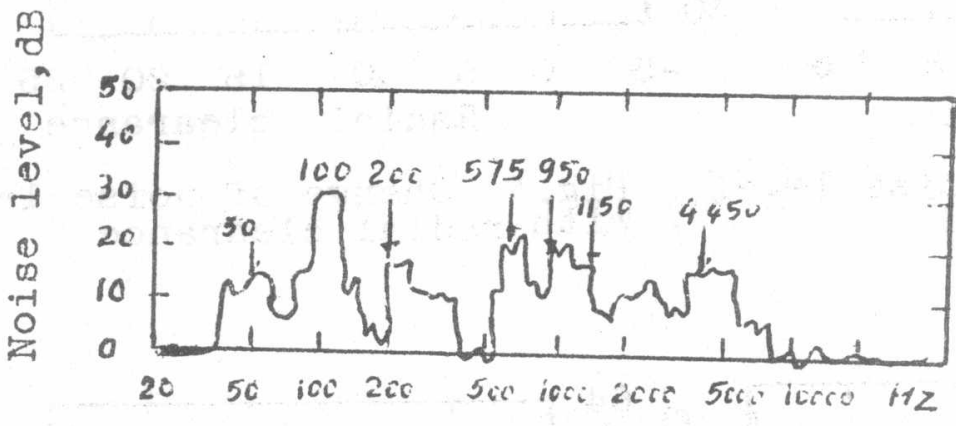

Fig. 5 Frequency spectrum of test motor noise

TABLE

Classification of motor noise

\begin{tabular}{|c|c|c|}
\hline Classification & Frequency, $\mathrm{Hz}$ & Source \\
\hline $\begin{array}{l}\text { Rotating noise } \\
\text { Electromagnetic } \\
\text { noise } \\
\text { Ventilating noise } \\
\text { Stator resonant } \\
\text { noise } \\
\text { Bearing noise }\end{array}$ & $\begin{array}{l}\text { Rotating speed } \\
50,100,200,950 \\
1150,4450 \\
160-500 \\
500-610 \\
\text { More than1000 }\end{array}$ & $\begin{array}{l}\text { Dynamic unbalance of } \\
\text { rotor } \\
\text { Eccentricity of rotor } \\
\text { and varlations of } \\
\text { radial magnetic field } \\
\text { Air draft generated by } \\
\text { fan } \\
\text { Natural vibrations of } \\
\text { stator due to vibrate } \\
\text { lons of bearing and air } \\
\text { Bearings }\end{array}$ \\
\hline
\end{tabular}




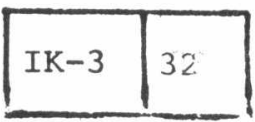

$r$
SECOND A.M.E. CONFERENCE

6 - 8 May 1986, Cairo

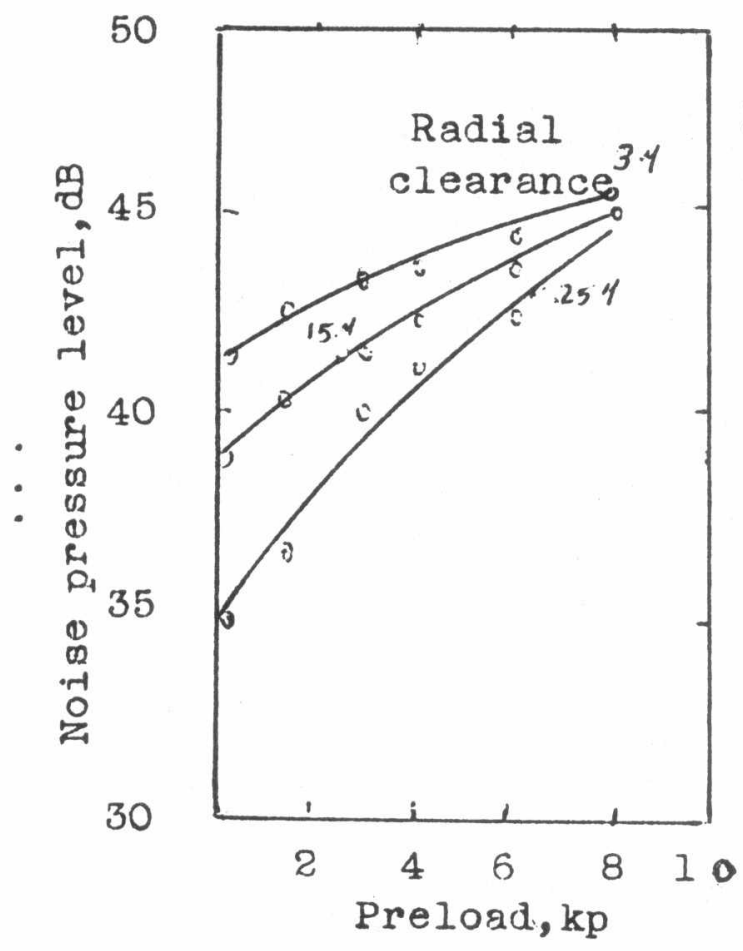

Fig. 6 Change of noise level with bearing preload

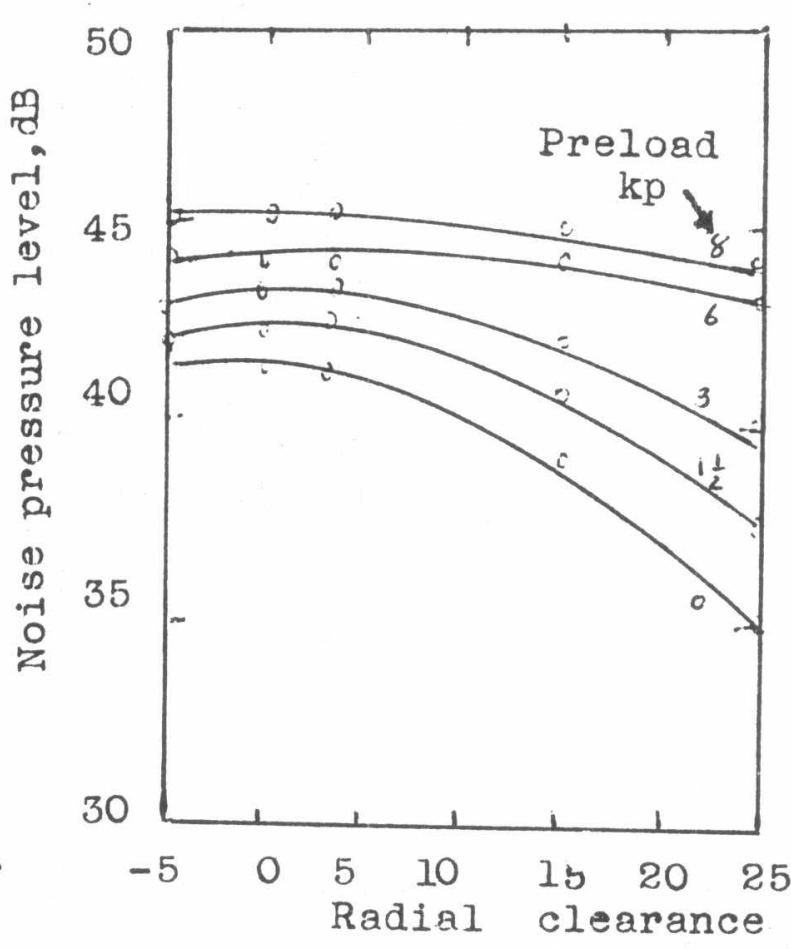

Fig. 7 Change of noise level with radial clearance

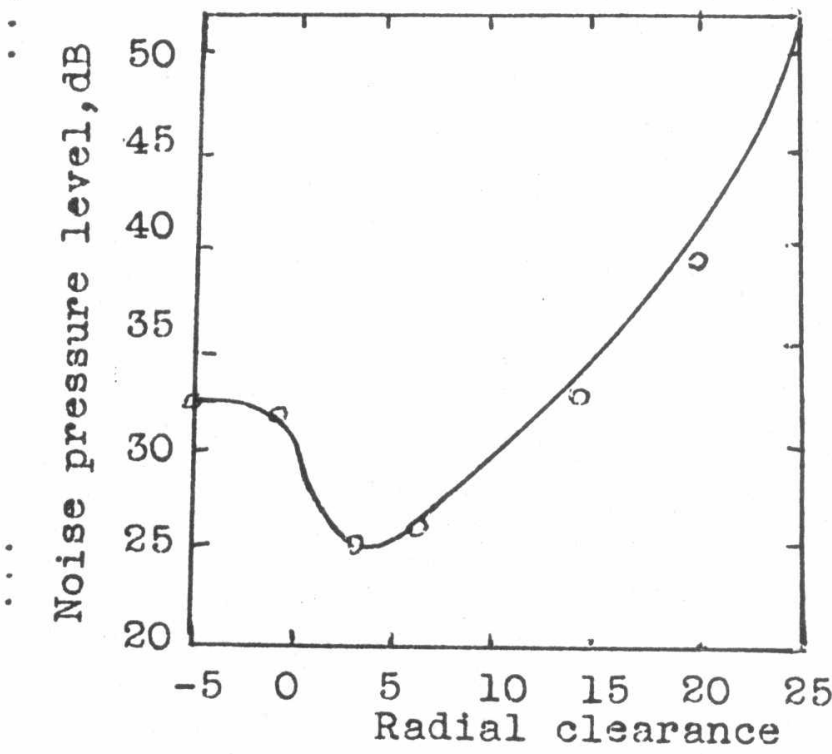

Fig. 8 Change of stator resonant noise with radial clearance

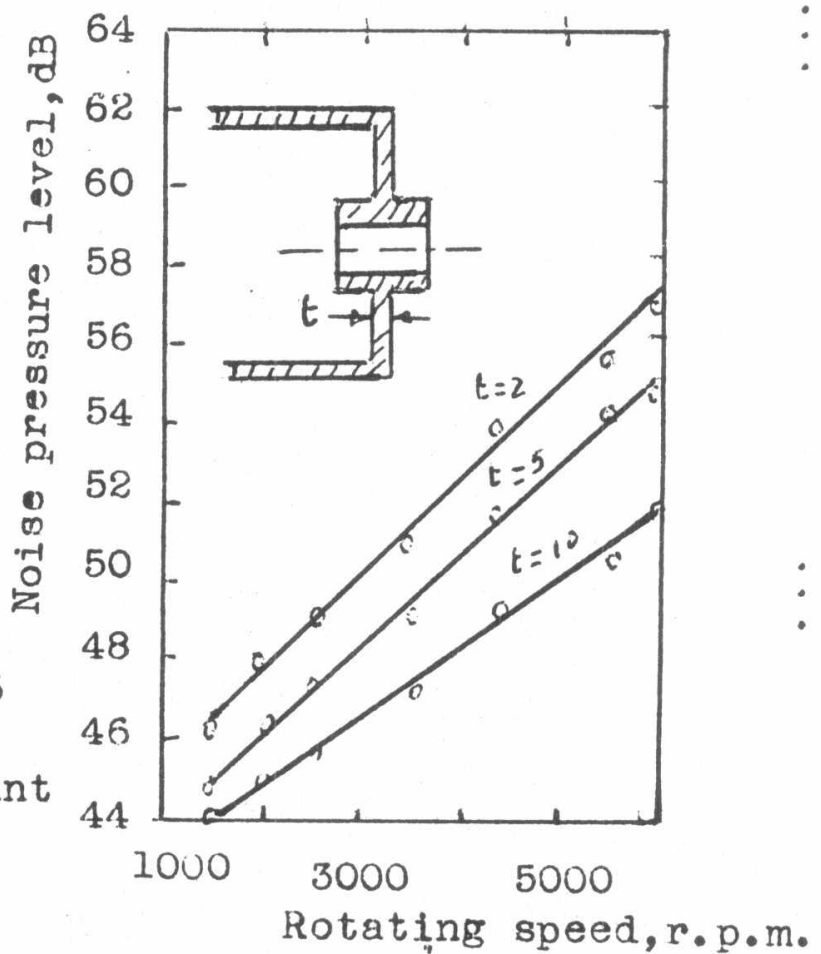

Fig. 9 Change of noise level with rotating speed and web thickness 


\begin{tabular}{|l|l|}
\hline $1 k-3$ & 33 \\
\hline
\end{tabular}

$r$
SECOND A.M.E. CONFERENCE

6 - 8 May 1986 , Cairo

Fig. 4 shows the maximum noise levels for the motor running on plain bearings and rolling bearings and with the fan and without the fan. It has been noticed that, in. some harmonics, noise levels are less when the motor is running on ball bearings and with the fan.

Fig. 5 shows the frequency spectrum for the motor running at $1500 \mathrm{r} . \mathrm{p} . \mathrm{m}$. without a fan and on sliding bearings, thus the main sources of noise are nearly the electromagnetic forces.

Fig. 6 shows the change in motor noise level following the - change of bearing preloading and Fig. 7 shows these changes with the change of bearing radial clearance.

Fig. 8 shows the change of motor noise level with the change of rigidity of the bracket at different rotating speeds.

\section{CONCLUSIONS}

4. I It is possible to divide and measure noise of small a.c. induction motor to electromagnetic, ventilating, stator resonant and bearing noises.

4.2 Stator resonant noise and bearing noise change with the amount of bearing preloading and radial clearance.

4. 3 Bearing noise is affected by the rigidity of the bracket - and high rigidity brackets damp motor noise.

\section{RAFRENCES}

1. Handbook of noise control by Harris, C.M.,1979.

2. I.E.E.E. test procedure for air borne sound measurement and rotary electric machinery.

3. Technical information bulletin, MG-BI, National Electrical Manufacturers Association, NAMA.

4. Noise reduction, Beranek, Leo L., 1960.

5. Noise reduction by covers, Noise Control, vol $I$, no.2

p. 19 March 1955, Engstrom, J.R. 
